\title{
Novel methods to identify biologically relevant genes for leukemia and prostate cancer from gene expression profiles
}

\author{
Austin H Chen*1, Yin-Wu Tsau² and Ching-Heng Lin²
}

\begin{abstract}
Background: High-throughput microarray experiments now permit researchers to screen thousands of genes simultaneously and determine the different expression levels of genes in normal or cancerous tissues. In this paper, we address the challenge of selecting a relevant and manageable subset of genes from a large microarray dataset. Currently, most gene selection methods focus on identifying a set of genes that can further improve classification accuracy. Few or none of these small sets of genes, however, are biologically relevant (i.e. supported by medical evidence). To deal with this critical issue, we propose two novel methods that can identify biologically relevant genes concerning cancers.
\end{abstract}

Results: In this paper, we propose two novel techniques, entitled random forest gene selection (RFGS) and support vector sampling technique (SVST). Compared with results from six other methods developed in this paper, we demonstrate experimentally that RFGS and SVST can identify more biologically relevant genes in patients with leukemia or prostate cancer. Among the top 25 genes selected using SVST method, 15 genes were biologically relevant genes in patients with leukemia and 13 genes were biologically relevant genes in patients with prostate cancer. Meanwhile, the RFGS method, while less effective than SVST, still identified an average of 9 biologically relevant genes in both leukemia and prostate cancers. In contrast to traditional statistical methods, which only identify less than 8 genes in patients with leukemia and less than 8 genes in patients with prostate cancer, our methods yield significantly better results.

Conclusions: Our proposed SVST and RFGS methods are novel approaches that can identify a greater number of biologically relevant genes. These methods have been successfully applied to both leukemia and prostate cancers. Research in the fields of biology and medicine should benefit from the identification of biologically relevant genes by confirming recent discoveries in cancer research or suggesting new avenues for exploration.

\section{Background}

The completion of the Human Genome Project (HGP) has been recognized as a great achievement in the study of biomedicine; the project not only provided comprehensive information on the human genome but also inspired new ways to study human diseases such as cancers. Concurrent with the advancement of the HGP, several high-throughput and rapid gene function analysis techniques were developed. Among them, microarray may be the most mature technique, and it has become a

* Correspondence: achen@mail.tcu.edu.tw

${ }^{1}$ Department of Medical Informatics, Tzu Chi University, No.701, Sec. 3, Jhongyang Rd. Hualien City, Hualien County 97004, Taiwan Full list of author information is available at the end of the article major data resource in gene function research [1-3]. Over the past few years, microarray-based gene expression profiling has proven to be a promising approach in predicting cancer classification and prognosis outcomes [46]. In most cases, cancer diagnosis depends on using a complex combination of clinical and histopathological data. However, it is often difficult or impossible to recognize tumor types in atypical instances [7]. To translate microarray data into functional physiological information, a set of genes with the maximum amount of information and a minimum amount of noise is needed. For example, diagnostic tests that measure the abundance of a given protein in serum may be derived from a small subset of biologically relevant genes. 
In cancer classification, one of the reasons one may wish to select a minimum set of genes is to avoid an overfitting problem caused by attempting to apply a large number of genes to a small number of samples. There are several statistical and machine learning techniques such as t-Test, k-nearest neighbors, clustering methods [8], self organizing maps (SOM) [9], genetic algorithm [10], backpropagation neural network [11-13], probabilistic neural network, decision tree [14], random forest [15], and support vector machines (SVM) [16,17] that have been applied in selecting informative genes. Although these methods can select smaller set of informative genes, only a small percentage of these so called "informative" genes are biologically relevant as proved by medical experiments. Our goal in this paper, therefore, is to best identify biologically relevant genes from a small set of genes using our proposed methods. We present a novel approach that addresses different considerations, including: (1) the identification of quality samples, (2) the selection of a small set of informative genes from these samples, (3) the comparison of these genes with medical literature, and (4) the interpretation of their biological relevance.

Prostate cancer and leukemia are very common cancers in the United States. In 2007 alone, approximately 24800 new cases and 12320 deaths among males were attributed to leukemia. Among males age 40 and below, leukemia is the most common fatal cancer. Meanwhile, 19440 new cases and 9470 deaths among females were attributed to leukemia, and it is the leading cause of cancer death among females below age 20. Acute lymphocytic leukemia (ALL) is the most common cancer in children age 14 and below. Prostate cancer, on the other hand, in 2007 accounted for almost 29\% (218 890) of incidents in males. For men age 80 and older, prostate cancer is the second most common cause of cancer death. Based on cases diagnosed between 1996 and 2002, an estimated $91 \%$ of these new cases are expected to be diagnosed at the local or regional level, for which the 5 -year relative survival rate approaches $100 \%[18,19]$. Therefore, the identification of biologically relevant genes is of fundamental and practical interest. The examination of these genes may be useful in confirming recent discoveries in cancer research or suggesting new methods for exploration.

In this paper, we examine eight methods for identifying biologically relevant genes. Among them are six statistics methods $[20,21]$ and two machine learning methods. The statistics methods include three parametric methods: Signal-to-noise ratio (SNR) [22-24], t-Test [23,25], and Least Significant Difference (LSD) [13,26]. They also include three nonparametric methods: Threshold Number of Misclassification (TNoM) [25], Minimum Distance to Modal Ranking (MDMR) $[27,28]$, and Weighted Punishment on Overlap (WEPO) $[29,30]$. In addition to these six statistics methods, we propose two new methods using machine learning approaches: Random forest gene selection (RFGS) and Support Vector Sampling technique (SVST). For each one of these, we first introduce some underlying theory and the process of computation. Then, we apply these methods to both leukemia and prostate cancer datasets. We compare the top 25 genes identified by each method with those identified within current medical literature, thus pinpointing the biological genes most related to leukemia and prostate cancer. The results show that our proposed SVST method is significantly better than statistical methods for identifying relevant biological genes in leukemia and prostate cancer.

The remainder of this paper is organized as follows: Section 2 discusses the various statistics-based gene selection methods considered in the paper. Section 3 describes our two proposed machine learning methods. Section 4 describes the experiment results and discusses leukemia and prostate cancer. Finally, Section 5 presents the conclusions of our study.

\section{Statistics-Based Gene Selection Methods}

Gene selection is widely used to select target genes in the diagnosis of cancers. One of the primary goals of gene selection is to avoid the over-fitting problems caused by the high dimensions and relatively small number of samples of microarray data. Theoretically, in cancer classification, only informative genes which are highly related to particular classes (or subtypes) should be selected [24]. In microarray data analysis, the challenge is to select informative genes that clearly differentiate the classes. Since the number of informative genes is very small compared to the total number of genes in each experiment, utilizing a better search technique is critical. We divide such techniques into two main categories: statistics-based methods and machine learning-based methods. In this section, we will discuss the statistics methods while addressing the machine learning-based methods in the next section.

The statistics methods rank or score the discriminability of each gene based on its own gene expression patterns. Both parametric and nonparametric approaches for estimations of discriminability have been proposed. The parametric estimation approach assesses the discriminability of genes using a variety of statistical analyses, including Signal-to-noise ratio (SNR), t-Test, and Least Significant Difference (LSD). Parametric estimation depends on exact expression levels and the number of replicate samples. The statistical criteria are based on the assumption that the data comes from some kind of distribution. Each parametric approach puts different weights on the variance and number of samples of the criteria. In this study, we use three parametric methods: Signal-tonoise ratio (SNR), t-Test, and Least Significant Difference 
(LSD). A gene is considered more informative if it possesses a larger corresponding score.

\section{Signal-to-Noise Ratio (SNR)}

Each dataset consists of $m$ samples and $n$ genes. For each gene $g_{i}$, we normalize the gene expression data by subtracting the mean (signal) and then dividing by the standard deviation of the expression value (noise). Every sample is labeled with $\{+1,-1\}$ (e.g. normal or cancer). We use the following formula to calculate each gene's F score.

$$
F\left(g_{i}\right)=\frac{\left|\mu^{+1}\left(g_{i}\right)-\mu^{-1}\left(g_{i}\right)\right|}{\sigma^{+1}\left(g_{i}\right)+\sigma^{-1}\left(g_{i}\right)}
$$

The $\mu$ and $\sigma$ characters represent the mean and the standard deviation of samples in each class (either +1 or 1 ) individually. We rank these genes by F score and then select the top 25 gene sets as the features.

\section{t-Test}

The $\mathrm{t}$-Test assesses whether the means of two groups are statistically different from each other. In microarray data analysis, the unpaired two-sample $t$-Test is often used since samples may be derived from different experiments and may have different distributions. We calculate the discriminative power of the $i$ th gene using a t-Test,

$$
T\left(g_{i}\right)=\frac{\left|\mu^{+1}\left(g_{i}\right)-\mu^{-1}\left(g_{i}\right)\right|}{\sqrt{\frac{\sigma^{+1}\left(g_{i}\right)^{2}}{M^{+1}-1}+\frac{\sigma^{-1}\left(g_{i}\right)^{2}}{M^{-1}-1}}}
$$

where $M+$ and $M$ - are the sample sizes and $\mu$ and $\sigma$ are the respective mean and standard deviation of samples in each class (either +1 or -1 ). We rank these genes with a $\mathrm{T}$ score and then select the top 25 gene sets as the features.

\section{Least Significant Difference (LSD)}

Least Significant Difference, also called the Fisher criterion, is a classical measure to assess the degree of separation between two classes. It is a t-Test-like statistic. The score for gene $i$ is defined as

$$
\mathrm{F}\left(g_{i}\right)=\frac{\left|\mu^{+1}\left(g_{i}\right)-\mu^{-1}\left(g_{i}\right)\right|}{\sigma^{+1}\left(g_{i}\right)^{2}+\sigma^{-1}\left(g_{i}\right)^{2}}
$$

where $\mu$ and $\sigma$ are the respective mean and standard deviation of samples in each class (either +1 or -1 ). We rank these genes by $\mathrm{F}$ score and then select the top 25 gene sets as the features.
In contrast to the parametric approach, nonparametric approaches rank samples of each gene using their expression level and punish the disorders that damage a perfect sample split. The less the punishment, the smaller the score a gene receives. This means that a gene is more informative if it has a smaller corresponding score. In this study, we use three nonparametric methods: Threshold Number of Misclassification (TNoM), Minimum Distance to Modal Ranking (MDMR), and Weighted Punishment on Overlap (WEPO).

\section{Threshold Number of Misclassification (TNoM)}

TNoM assumes that an informative gene has different values between the two classes, and thus we are able to separate these using a threshold value. A decision rule corresponding to a given expression level, such as sign $(a x+b)$, is used to score the given gene and predict the unknown class. TNoM looks to select the values of $a$ and $b$ in order to minimize the number of errors:

$$
\begin{aligned}
& \operatorname{Err}(\mathrm{a}, \mathrm{b} \mid \mathrm{i})=\sum_{\mathrm{k}} \lambda\left\{\lambda(\mathrm{i}) \neq \operatorname{sign}\left(\mathrm{a} \times \mathrm{G}(\mathrm{i})_{\mathrm{k}}+\mathrm{b}\right)\right\} \\
& \operatorname{TNoM}(\mathrm{i})=\min _{\mathrm{a}, \mathrm{b}} \operatorname{Err}(\mathrm{a}, \mathrm{b} \mid \mathrm{i})
\end{aligned}
$$

We then rank these genes with a TNoM score and select the top 25 gene sets as the features.

\section{Minimum Distance to Modal Ranking (MDMR)}

The MDMR method first ranks all the sample values of a gene and then computes the minimum distance between these ranks and a modal rank. The ranking algorithm, described by Park et al [28], is used in this study. A score is defined as the minimum number of consecutive swaps needed to arrive at a perfect split of two classes. A score of 0 represents the gene that can split two classes exactly. The MDMR score is defined as

$$
\operatorname{MDMR}(\mathrm{i})=\sum_{\mathrm{p} \in-1} \sum_{\mathrm{q} \in+1} \mathrm{~h}\left(\mathrm{x}_{\mathrm{p}}-\mathrm{x}_{\mathrm{q}}\right)
$$

where $\mathrm{h}(\mathrm{x})$ is the indicator function

$$
h(x)=\left\{\begin{array}{l}
1, x>0 \\
0, x \leq 0
\end{array}\right.
$$

We then rank these genes with an MDMR score and select the top 25 genes for the study.

\section{Weighted Punishment on Overlap (WEPO)}

Chung et al. [30] proposed the WEPO method to reduce possible loss of information when using the TNoM or 
MDMR methods. Because genes with identical ordered expression data may not have the same discriminative power, WEPO introduces the z-score into the rank swapping scheme in order to avoid this problem. For gene $k$, the expression levels of samples are first normalized via zscore to eliminate the problem of scaling. The $\mathrm{z}$-score is defined as

$$
\mathrm{z}_{\mathrm{ki}}=\frac{\mathrm{G}(\mathrm{i}) \mathrm{k}-\mu_{\mathrm{i}}}{\operatorname{MAD}(\mathrm{i})}
$$

where $\mu$ is the sample mean and MAD is the mean absolute deviation of gene $k$. The punished score of each gene is calculated by estimating the overlapping regions of the two classes. The punishment is defined as

$$
\mathrm{WEPO}(\mathrm{i})=\sum_{\mathrm{p} \in+1} \sum_{\mathrm{q} \in-1} \Psi\left(\mathrm{z}_{\mathrm{pi}}-\mathrm{z}_{\mathrm{qi}}\right), \Psi(\mathrm{z})=\left\{\begin{array}{c}
|z|, \mathrm{z}>0 \\
0, \mathrm{z} \leq 0
\end{array}\right.
$$

\section{Machine Learning-Based Gene Selection Methods}

Identifying biologically relevant genes, such as cancerrelated genes, from microarray gene expression data is one of the most important areas in modern medical research. In addition to the six statistical methods described in the previous section, we also propose two machine learning-based gene selection methods: Random Forest Gene Selection (RFGS) and Support Vector Sampling Technique (SVST).

\section{Random Forest Gene Selection (RFGS)}

Random forest is an algorithm for classification developed by Leo Breiman [31] that uses an ensemble of classification trees. Each of the classification trees is built using a bootstrap sample of the data, and at each split the candidate set of variables is comprised of a random subset. Thus, random forest uses both bagging and random variable selection for tree building.

In this paper, we propose a random forest concept to identify biologically relevant genes. The flowchart of our approach is shown in Figure 1. We first randomly divide all genes into 1000 groups; for example, there are approximately 7 genes in each group for the leukemia dataset and 13 genes in each group for the prostate cancer dataset. When all genes are randomly assigned into a group, we then build up a decision tree for each group. The most significant gene in each tree will serve as the root gene, and these root genes are marked by adding a number in the gene array. After the first cycle is completed, we initiate another cycle by again randomly assigning all genes, and this process is repeated for 100 cycles. The more frequently a gene is selected as the root, the higher a score it will receive. After 100 cycles, all genes will be ranked based on their score. In this paper, we select the top 25 genes and confirm them based on supporting evidence culled from current medical literature. If the genes are found to have a relationship with the target cancers, we call them "biologically relevant genes". Because the random forest approach may generate different biological genes each time, we run the code 10 times. Those genes which on average appear most consistently within the top 25 are used in comparison with the results of other methods.

This approach is displayed in the following pseudo code, where $X$ is the cancer's gene expression data (containing $S$ samples $G$ and genes) and the $Y^{S}$ is the label of each sample.

The Pseudo Code of the Random Forest Gene Selection Method

$$
\text { Input: } X=\left\{x_{G}^{S}, Y^{S}\right\}, S=1 . . s, G=1 . . g, Y^{S} \quad\{-1,1\}, X
$$
$\operatorname{Rg}$

$s=$ number of samples, $g=$ number of genes

Output: $n$ top genes

1. begin

2. for $i=1$ to $S$

3. do normalize $X$

4. end

5. for $I=1$ to $N(N=100$ used here $)$

6. while (All genes assigned completely)

7. Randomly assign all genes into $M$ groups $(M=$ 1000 used here)

8. for $J=1$ to $M$

9. Build up a decision tree on each group

10. Mark the root of each group

11. end

12. end

13. Rank gene following the number of marks for every gene

14. Select the top 25 genes from the ranking list

15. Confirm the genes with biological evidence from public resources

16. Calculate the average biological genes found in the top 25 genes

\section{Support Vector Sampling Technique (SVST)}

In the ongoing effort to improve the accuracy of cancer classification, many machine learning methods have been developed over the past few years. Among them, SVM is arguably one of the best methods. Although the SVM classification method has been widely used in the machine learning domain, there is little research focused on the actual support vectors. These support vectors have several computational and learning theoretic consequences [32]. Gene selection is a common way to avoid the high dimensional feature problem; however, the 


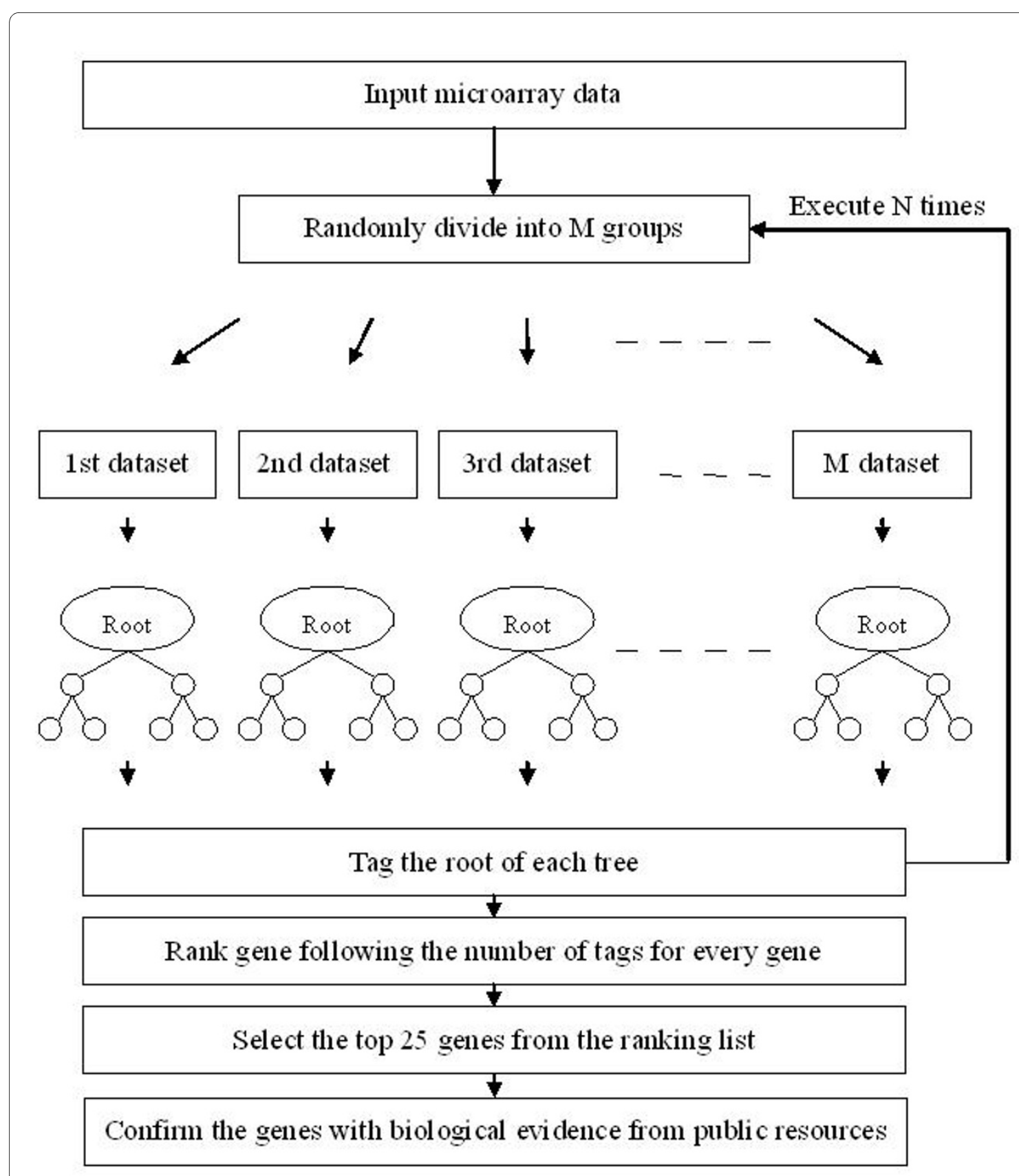

Figure 1 The flowchart of the random forest gene selection method.

majority of past research has applied gene selection algorithms using all available samples. The accuracy of SVM is largely dependent on a hyperplane that can clearly separate different classes, and many samples may be outliers or may be separated incorrectly. Thus, using all samples could cause some degree of inaccuracy in classification performance.
In this paper, we develop a new method to identify biologically relevant genes using only quality samples which are located on support vectors. We assume that the use of support vectors is critical in eliminating irrelevant tissue composition-related genes. We called this method the support vector sampling technique (SVST). Our hypothesis is that by using samples located only on support vec- 
tors, we have a higher probability of identifying more relevant genes. To verify this hypothesis experimentally, we compared SVST with other statistical methods using two cancer datasets. SVST is a two-step process which includes first selecting support vector samples and then performing the SNR gene selection method. This approach allows us to narrow the field to only the most relevant samples in order to select the most biologically relevant genes.

The approach process is displayed in the following pseudo code. Xis the cancer's gene expression data, containing $S$ samples and $G$ genes, and the $Y^{S}$ is the label of each sample.

The Pseudo Code of the SVST Method

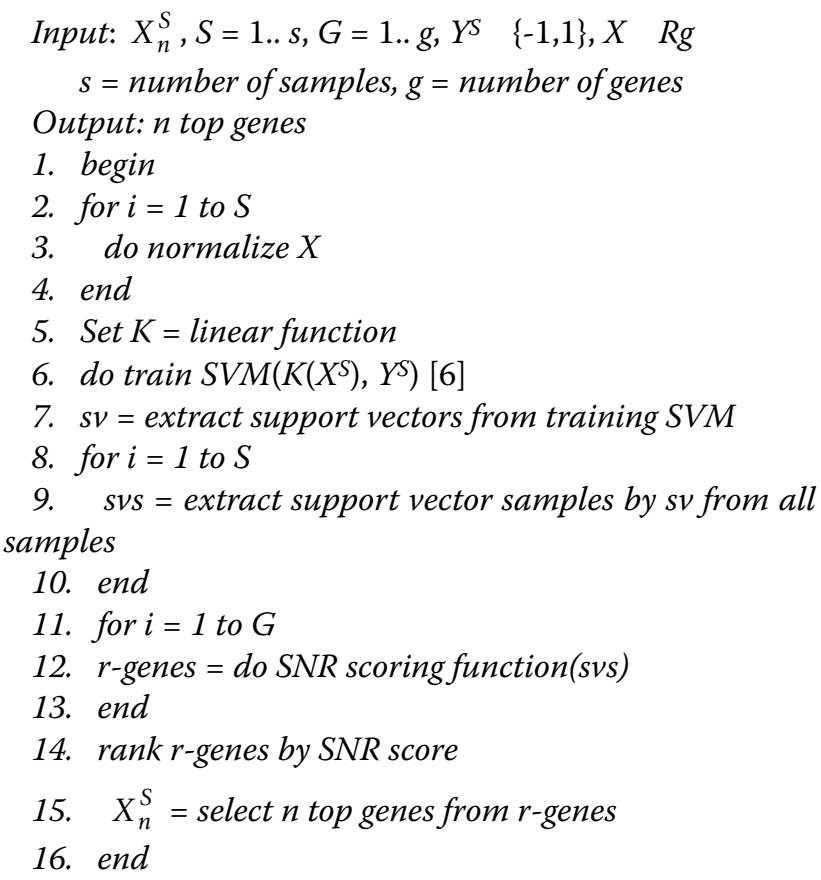

\section{Theoretical basis of the SVST}

The SVST is briefly described as follows. A binary SVM attempts to find a hyperplane which maximizes the "margin" between two classes $(+1 /-1)$. Let

$$
\left\{X^{i}, Y^{i}\right\}, i=1 \ldots j, Y^{i} \in\{-1,1\}, X \in R g
$$

be the gene expression data with positive and negative class labels, and the SVM learning algorithm should find a maximized separating hyperplane

$$
W \bullet X+b=0
$$

where $W$ is the $\mathrm{n}$-dimensional vector (called the normal vector) that is perpendicular to the hyperplane, and $b$ is the bias. The SVM decision function is shown in formula
(1), where $\alpha_{i}$ are positive real numbers and $\varphi$ is the mapping function

$$
W^{T} \phi(X)+b=\sum_{i=1}^{j} \alpha_{i} Y_{i} \phi\left(X_{i}\right)^{T} \phi(X)+b
$$

Only of $\varphi\left(X_{i}\right)$ of $\alpha_{i}>0$ would be used, and these points are support vectors. The support vectors lie close to the separating hyperplane (shown in Figure 2). $\alpha_{i}$ represents non-negative Lagrange multipliers, and it is used to discriminate every piece of training data which has a different influence on the hyperplane in high dimension feature spaces. To explain the meaning of $\alpha_{i}$, we first maximize the Lagrange problem:

$$
L_{D} \equiv \sum_{i=1}^{j} \alpha_{i}-\frac{1}{2} \sum_{i, m=1}^{j} \alpha_{i} \alpha_{m} Y_{i} Y_{m} X_{i} \cdot X_{m}
$$

When $\alpha_{i}=0$ then $L_{D}=0$ in formula (2), as in this case, $\alpha_{i}$ means that the $\mathrm{i}$ th data has no influence on the hyperplane; therefore, this sample is correctly classified by the hyperplane (such as point $\mathrm{A}$ in Figure 2).

When $0<\alpha_{i}<\mathrm{C}$, where $\mathrm{C}>0$ is the penalty parameter of the error term, the Lagrange problem $L_{D}$ is subject to

$$
\sum_{i=1}^{j} \alpha_{i} Y_{i}=0
$$

Therefore, $L_{D}=\alpha_{i}$, and under this circumstance, $\alpha_{i}$ means that the ith data has a degree of influence on the hyperplane (such as point B in Figure 2).

When $\alpha_{i}=\mathrm{C}$, the Lagrange problem $L_{D}$ is subject to

$$
\frac{1}{2} \sum_{i, m=1}^{j} \alpha_{i} \alpha_{m} Y_{i} Y_{m} X_{i} \cdot X_{m}>\alpha_{i}
$$

$L_{D}$ is negative, and therefore, $\alpha_{i}$ means the ith data is incorrectly classified by the hyperplane (such as point $\mathrm{C}$ in Figure 2). Each $\alpha_{i}$ determines the degree by which each training example influences the SVM function. Because the majority of the training examples do not affect the SVM function, most of the $\alpha_{i}$ are 0 . We can then infer that these support vectors should contain the desired strong classification information. By extracting only the samples (such as point B) located on the hyperplane, we can run a 


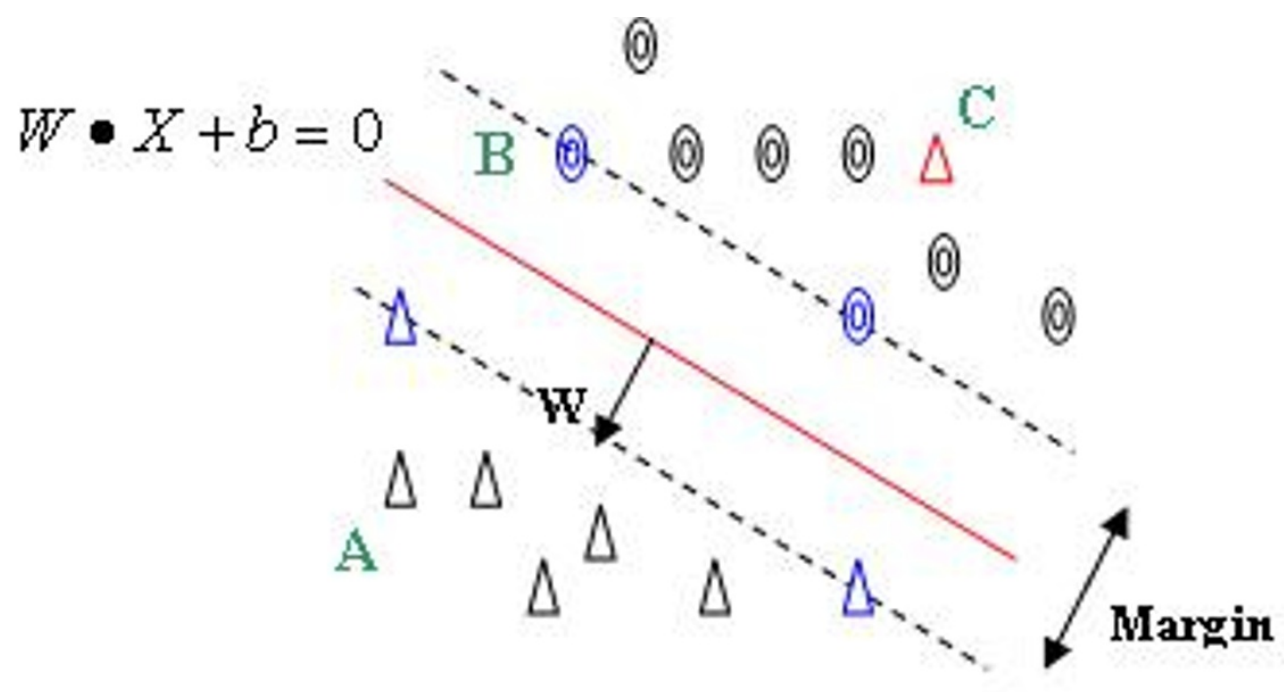

Figure 2 The hyperplane and the support vectors. The red line is the hyperplane which separates the two classes of samples. The blue points are the support vectors. A is the right classified sample but has less influence on the hyperplane. B is the right classified sample and has influence on the hyperplane. $\mathrm{C}$ is the incorrectly classified sample.

gene selection algorithm that better identifies biologically relevant genes.

We applied our method to two microarray datasets for leukemia and prostate cancer. In order to simplify the selection of the SVM parameters, we tested several different settings to ascertain the best classification performance. The selection of SVM parameters used in our SVST method is summarized in Table 1 . These parameter settings may not be optimized settings; however, they are sufficient for the selection of quality support vectors. Using these parameter values, we found 32 support vector samples in 72 leukemia samples and 44 support vector samples in 102 prostate cancer samples. We then used these samples to find the most informative genes through the SNR gene selection algorithm.

\section{Results and Discussion}

In this paper, we experiment using two cancer gene expression microarray datasets: leukemia and prostate cancer. We chose this data not only out of concern for the

Table 1: Parameter settings in SVM for SVST method.

\begin{tabular}{cc}
\hline Parameter & Setting \\
\hline Kernel Type & Linear \\
\hline $\begin{array}{c}\text { Gamma [Default: } 1 / \text { (\# of } \\
\text { genes)] }\end{array}$ & $\begin{array}{c}1 / 7200 \text { for leukemia } 1 / 12600 \\
\text { for prostate cancer }\end{array}$ \\
\hline Cost & 1 \\
\hline
\end{tabular}

potential influence on human beings but also for the data's characteristics. Leukemia microarray data is easily classified; many cancer classification researchers consider this data as a performance comparison standard. Prostate cancer microarray data, however, is not easily classified. Therefore, utilizing both datasets provides a measurable way to demonstrate the benefits of our proposed methods.

\section{Application to the leukemia microarray dataset Leukemia dataset}

This original gene expression data was downloaded from http://www.genome.wi.mit.edu/MPR/[23]. The data contains 72 bone marrow or peripheral blood samples with either acute myeloid leukemia (AML) or acute lymphoblastic leukemia (ALL). The data set provides 7129 human genes produced by Affymetrix high-density olignucleotide microarrays. The intensity of gene expression is rescaled to normalize overall intensities for each microarray. Even though this data provides a plethora of genetic information, its feature dimension is too high for practical analysis. We need a selection method that can reduce this feature dimension.

\section{Identifying biologically relevant leukemia genes}

Table 2 compares the resulting biologically relevant genes in leukemia identified using the 8 methods. Among these 8 methods, WEPO finds the least number of biological genes at 5 genes, while TNoM identifies 6 genes. LSD and $\mathrm{t}$-Test both identify 7 biological genes. SNR and random forest identify 8 and 9 biological genes respectively. SVST and MDMR find the most biologically relevant genes, where SVST identified 15 and MDMR identified 12. Our 
Table 2: The biologically relevant genes found in leukemia.

\begin{tabular}{|c|c|c|c|c|c|c|c|c|}
\hline & SNR & t-TEST & LSD & TNoM & MDMR & WEPO & RFGS* & SVST \\
\hline Gene1 & ZYX & SNRPD1 & SNRPD1 & KLHDC10 & $Z Y X$ & PTMA & MGST1 & $Z Y X$ \\
\hline Gene2 & TCF3 & PRPF18 & LAMP2 & BTG2 & APLP2 & CXCR4 & CD63 & TCF3 \\
\hline Gene3 & CCND3 & LAMP2 & PRPF18 & CD68 & MGST1 & IFITM3 & SERPING1 & CD33 \\
\hline Gene4 & CST3 & PRKCl & PRKCl & EIF4A1 & CSTA & ADA & QSOX1 & CD63 \\
\hline Gene5 & CD33 & MSH2 & GTF2E2 & PFKL & CD63 & RPL23A & APLP2 & TCRA \\
\hline Gene6 & CD79A & GTF2E2 & MSH2 & LIPE & CTSD & & PLCB2 & SPTAN1 \\
\hline Gene7 & SPTAN1 & DCK & ALCAM & & LYN & & POU2AF1 & MPO \\
\hline Gene8 & $\begin{array}{c}\text { Macmarc } \\
\text { ks }\end{array}$ & & & & CLU & & CTSD & CST3 \\
\hline Gene9 & & & & & $\mathrm{FAH}$ & & ACADM & HOXA9 \\
\hline Gene10 & & & & & PLEK & & & CD79A \\
\hline Gene11 & & & & & MPO & & & $\begin{array}{c}\text { Macmarc } \\
\text { ks }\end{array}$ \\
\hline Gene12 & & & & & LRPAP1 & & & CCND3 \\
\hline Gene13 & & & & & & & & PSMB9 \\
\hline Gene14 & & & & & & & & IL18 \\
\hline Gene15 & & & & & & & & STOM \\
\hline
\end{tabular}

8

$$
7
$$

7
12

Comparison of biologically relevant genes in leukemia identified using 8 methods An * indicates the average number of biologically relevant genes found in the top 25 genes using the random forest gene selection method. proposed SVST method has the best performance in terms of identifying biologically relevant genes for leukemia.

For the random forest method, we can identify, on average, 9 biologically relevant genes from the top 25 ranked genes. In Table 2, we show the results of running the method 10 times and order the relevant genes by decreasing number of hits. As shown in Figure 3, 9 genes are recorded in the following order: MGST1 (7 hits), CD63 (6 hits), SERPING1 (5 hits), QSOX1 (5 hits), APLP2 (5 hits),
PLCB2 (5 hits), POU2AF1 (5 hits), CTSD (5 hits), and $A C A D M$ (4 hits).

Our proposed SVST method has the benefit of identifying more biologically relevant genes. For example, 15 genes $(60 \%)$ were found to be biologically relevant to leukemia among the top 25 ranked genes selected using the SVST method. Table 3 describes the gene names and their possible function. The medical literature regarding each gene is included in the same table. 


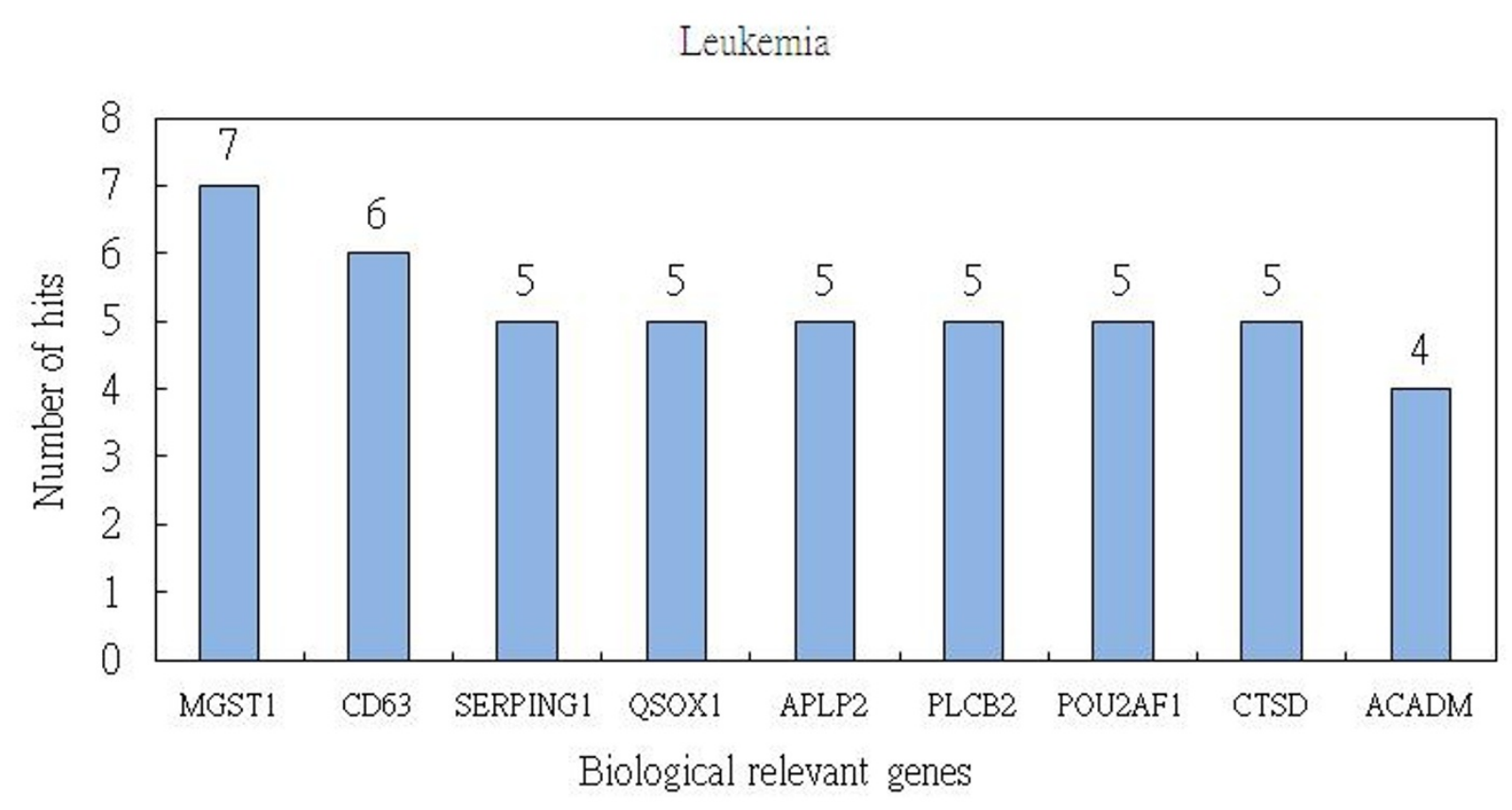

Figure 3 The average number of hits generated by the random forest method regarding biologically relevant genes in leukemia

In this section, we individually examine these 15 genes for relevance in the diagnosis of leukemia. All 15 genes have some relevance to leukemia and deserve a more detailed analysis to understand their role in the cancer's development. The role of some of these biologically relevant genes can be easily explained because they code for proteins whose role in leukemia has been long identified and widely studied. Such is the case of the HoxA9 gene, where Hoxa9 collaborates with other genes to produce highly aggressive acute leukemic disease [33]. The other example is the Macmarcks gene, where tumor necrosis factor-alpha rapidly stimulates Macmarcks gene transcription in human promyelocytic leukemia cells [34]. The presence of some of the other genes in our list can be explained by recently published studies. For example, the role of the CD33 gene, $C D 33$, is a myeloid cell surface antigen that is expressed on blast cells in acute myeloid leukemia (AML) in a majority of all patients regardless of age or subtype of disease [35].

The role of the 15 genes in Table 3 is described as follows. The ZYX gene: Zyxin encodes a LIM domain protein localized at focal contacts in adherent erythroleukemia cells [36]. The TCF3 gene: The $t(1 ; 19)(q 23 ; p 13.3)$ is one of the most common chromosomal abnormalities in B-cell precursor acute lymphoblastic leukemia and usually gives rise to the TCF3-PBX1 fusion gene. The TCF3 gene has been shown to be involved in the majority of cases with a cytogenetically visible $\mathrm{t}(1 ; 19)$ translocation, while the remaining TCF3negative ALLs demonstrated breakpoint heterogeneity [37]. The CD63 gene: In the rat basophilic leukemia cell line, an antibody against CD63 (AD1) inhibited immunoglobulin $\mathrm{E}$ (IgE)-mediated histamine release, suggesting a role for CD63 in events associated with mediator release [38]. The TCRA gene: T-cell prolymphocytic leukemia is a sporadic, mature $\mathrm{T}$-cell disorder in which there is usually an aberrant T-cell receptor alpha (TCRA) rearrangement that activates the TCL1 or MTCP1-B1 oncogenes [39]. The SPTAN1 gene: In a human chronic myelogenous leukemia cell line with the Ph1 chromosome, K562, the SPTAN1 mapped centromeric to the translocation breakpoint, indicating that the alpha-fodrin gene is not translocated to the Ph1 chromosome in this cell line [40]. The $\mathbf{M P O}$ gene: The tumour cells were positive for CD68 (KP1), CD68 (PGM1), lysozyme and CD45. They were negative for MPO, CD15, CD163, TdT, CD117, T and B cell markers [41]. The CST3 gene: Sun Y explores differentially expressed genes in leukemia gene expression profiles and identifies main related genes in acute leukemia. The results show that in four patient/donor pairs with ALL, 5 up-regulated (RIZ, STK-1, T-cell leukemia/lymphoma $1 \mathrm{~A}, \mathrm{Cbp} / \mathrm{p} 300, \mathrm{Op} 18)$ and 1 down-regulated genes (hematopoietic proteoglycan core protein) were identified. In five patient/donor pairs with AML, 6 upregulated (STAT5B, ligand p62 for the Lck SH2, CST3, LTC4S, myeloid leukemia factor 2 and epb72) and 1 
Table 3: Functions of the biologically relevant genes found in leukemia.

\begin{tabular}{|c|c|c|}
\hline Gene Name & Gene Function & Evidence References \\
\hline ZYX & $\begin{array}{l}\text { Adhesion plaque protein. Binds alpha- } \\
\text { actinin and the CRP protein. May be a } \\
\text { component of a signal transduction } \\
\text { pathway that mediates adhesion- } \\
\text { stimulated changes in gene expression. }\end{array}$ & [36] \\
\hline TCF3 & $\begin{array}{l}\text { Heterodimers between TCF3 and tissue- } \\
\text { specific basic helix-loop-helix (bHLH) } \\
\text { proteins play major roles in determining } \\
\text { tissue-specific cell fate during } \\
\text { embryogenesis, like muscle or early B-cell } \\
\text { differentiation. Binds to the kappa-E2 site } \\
\text { in the kappa immunoglobulin gene } \\
\text { enhancer. }\end{array}$ & [37] \\
\hline CD33 & $\begin{array}{l}\text { In the immune response, may act as an } \\
\text { inhibitory receptor upon ligand induced } \\
\text { tyrosine phosphorylation by recruiting } \\
\text { cytoplasmic phosphatase(s). }\end{array}$ & [35] \\
\hline CD63 & $\begin{array}{l}\text { This antigen is associated with early stages } \\
\text { of melanoma tumor progression. May play } \\
\text { a role in growth regulation. Lysosome } \\
\text { membrane; Multi-pass membrane protein. } \\
\text { Late endosome membrane; Multi-pass } \\
\text { membrane protein. Note = Also found in } \\
\text { Weibel-Palade bodies of endothelial cells. } \\
\text { Located in platelet dense granules. } \\
\text { melanomas, hematopoietic cells, tissue } \\
\text { macrophages. }\end{array}$ & [38] \\
\hline TCRA & T cell receptor alpha-chain. & [39] \\
\hline SPTAN1 & $\begin{array}{l}\text { Fodrin, which seems to be involved in } \\
\text { secretion, interacts with calmodulin in a } \\
\text { calcium-dependent manner. }\end{array}$ & [40] \\
\hline MPO & $\begin{array}{l}\text { Part of the host defense system of } \\
\text { polymorphonuclear leukocytes. It is } \\
\text { responsible for microbicidal activity } \\
\text { against a wide range of organisms. }\end{array}$ & [41] \\
\hline CST3 & $\begin{array}{l}\text { As an inhibitor of cysteine proteinases, this } \\
\text { protein is thought to serve an important } \\
\text { physiological role as a local regulator of } \\
\text { this enzyme activity. }\end{array}$ & [42] \\
\hline HoxA9 & $\begin{array}{l}\text { Sequence-specific transcription factor } \\
\text { which is part of a developmental } \\
\text { regulatory system that provides cells with } \\
\text { specific positional identities on the } \\
\text { anterior-posterior axis. }\end{array}$ & [33] \\
\hline
\end{tabular}


Table 3: Functions of the biologically relevant genes found in leukemia. (Continued)

\begin{tabular}{|c|c|c|}
\hline CD79A & $\begin{array}{l}\text { Required in cooperation with CD79B for } \\
\text { initiation of the signal transduction } \\
\text { cascade activated by binding of antigen to } \\
\text { the B-cell antigen receptor complex. }\end{array}$ & [43] \\
\hline Macmarcks & $\begin{array}{l}\text { May be involved in coupling the protein } \\
\text { kinase } C \text { and calmodulin signal } \\
\text { transduction systems. }\end{array}$ & [34] \\
\hline CCND3 & $\begin{array}{l}\text { Essential for the control of the cell cycle at } \\
\text { the G1/S (start) transition. Potentiates the } \\
\text { transcriptional activity of ATF5. }\end{array}$ & [44] \\
\hline PSMB9 & $\begin{array}{l}\text { The proteasome is a multicatalytic } \\
\text { proteinase complex which is characterized } \\
\text { by its ability to cleave peptides with Arg, } \\
\text { Phe, Tyr, Leu, and Glu adjacent to the } \\
\text { leaving group at neutral or slightly basic } \\
\text { pH. The proteasome has an ATP- } \\
\text { dependent proteolytic activity. This } \\
\text { subunit is involved in antigen processing } \\
\text { to generate class I binding peptides. }\end{array}$ & [26] \\
\hline IL18 & $\begin{array}{l}\text { Augments natural killer cell activity in } \\
\text { spleen cells and stimulates interferon } \\
\text { gamma production in T-helper type I cells. }\end{array}$ & [45] \\
\hline STOM & $\begin{array}{l}\text { Interacting selectively with one or more } \\
\text { specific sites on a receptor molecule, a } \\
\text { macromolecule that undergoes } \\
\text { combination with a hormone, } \\
\text { neurotransmitter, drug or intracellular } \\
\text { messenger to initiate a change in cell } \\
\text { function. }\end{array}$ & [46] \\
\hline
\end{tabular}

The 15 biologically relevant genes found in the top 25 ranked genes in leukemia selected using the SVST method.

down-regulated genes (CCR5) were identified [42]. The $C D 79 A$ gene: Expression of the CD79A (MB-1) chain has been studied in leukemia and is shown to be present in most B lineage acute lymphoblastic leukemia [43]. The CCND3 gene: A 51-bp deletion was detected in CCND3 in a patient with normal karyotype acute myeloid leukemia [44]. The PSMB9 gene: PSMB9 (LMP2) is expressed both in normal EBV latency and EBV-associated pathologies. EBV is associated with a variety of haematopoietic cancers such as African Burkitt's lymphoma, Hodgkin's, and adult T-cell leukemia [26]. The IL18 gene: IL18 (IGIF) proposed to be designated as IL-18, selectively upregulates ICAM-1 expression in KG-1 cells, a human myelomonocytic cell line, human IL-18 was measurable in the plasma of leukemia patients [45]. The STOM gene: STORP is homologous to the STOM (Epb72) gene coding for the erythrocyte band 7 integral membrane proteins or stomatin. The STORP gene is positioned $2 \mathrm{~kb}$ upstream of the promyelocytic leukemia gene in a headto-head configuration [46].

\section{Application to the prostate cancer microarray dataset Prostate cancer dataset}

The original gene expression data for prostate cancers is available at http://www.genome.wi.mit.edu/cgi-bin/cancer/datasets.cgi[ [47]. The dataset contains expression levels for 52 prostate tumor samples and 50 normal samples. Each sample contains 12600 genes measured using Afffymertix oligonucleotide arrays. We set the tumor sample to $(-1)$ and the normal samples to $(+1)$, and we then merged these data sets together for the 8 methods.

\section{Identifying biologically relevant prostate cancer genes}

To complete our study, we proceed similarly with the prostate cancer data by running our 8 gene selection methods on the entire dataset of 102 samples. The comparison of biologically relevant genes in prostate cancer identified using these 8 methods are shown in Table 4 . 
Table 4: The biologically relevant genes found in prostate cancer.

\begin{tabular}{|c|c|c|c|c|c|c|c|c|}
\hline & SNR & t-Test & LSD & TNoM & MDMR & WEPO & RFGS* & SVST \\
\hline Gene1 & HPN & UCK2 & UCK2 & NFIX & HPN & NF2 & PTGDS & HPN \\
\hline Gene2 & PTGDS & LPIN1 & LPIN1 & FOXG1 & PDIA5 & PTGDS & HPN & NELL2 \\
\hline Gene3 & NELL2 & KIAA0746 & KIAA0746 & PML & ICA1 & KLK3 & CLU & PTGDS \\
\hline Gene4 & S100A4 & GNB2L1 & GNB2L1 & & AGR2 & $\mathrm{CLU}$ & NELL2 & S100A4 \\
\hline Gene5 & TARP & CAV2 & CAV2 & & KLK3 & MYL6 & SERPINF1 & TNFSF10 \\
\hline Gene6 & COL4A6 & IGBP1 & IGBP1 & & UAP1 & FLNA & HSPA8 & SERBP1 \\
\hline Gene7 & ANGPT1 & CASP3 & CASP3 & & FBP1 & SERPING1 & XBP1 & RBP1 \\
\hline Gene8 & RBP1 & DOPEY2 & DOPEY2 & & & ACTG2 & ALCAM & GSTM1 \\
\hline Gene9 & GSTM1 & PDIA5 & PDIA5 & & & & AGR2 & ANGPT1 \\
\hline Gene10 & & & & & & & & LMO3 \\
\hline Gene11 & & & & & & & & COL4A6 \\
\hline Gene12 & & & & & & & & $\mathrm{DIO} 2$ \\
\hline Gene13 & & & & & & & & TARP \\
\hline
\end{tabular}

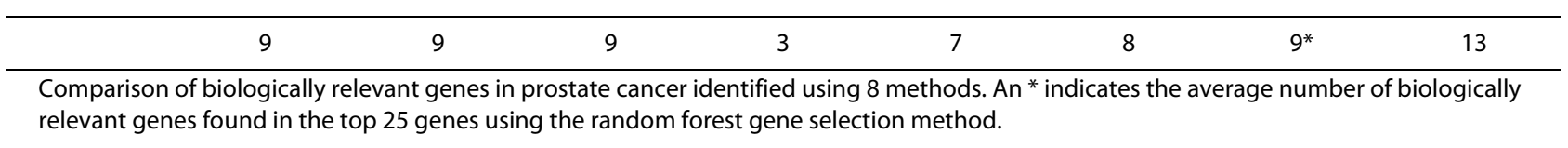

Among these 8 methods, TNoM finds the least number of genes at 3 genes. The MDMR and WEPO methods identify 7 genes and 8 genes respectively. All the following four methods (SNR, LSD, t-Test, and Random forest) are in the next group, where they identify 9 biologically relevant genes. SVST method, once again, is capable of finding the most at 13 biologically relevant genes. Among these 8 methods, our proposed SVST method has the best performance.

For the random forest method, we identify, on average, 9 biologically relevant genes in the top 25 ranked genes. In Table 2, we show the results gathered from running the method 10 times and order the biologically relevant genes by decreasing of number of hits. As shown in Figure 4, these 9 genes are recorded in the following order: PTGDS (9 hits), HPN (8 hits), CLU (6 hits), NELL2 (6 hits),
SERPINF1 (6 hits), HSPA8 (5 hits), XBP1 (4 hits), ALCAM (4 hits), and AGR2 (4 hits).

Table 5 lists 13 genes found to be biologically relevant to prostate cancer among the top 25 ranked genes selected using the SVST method. The possible function of each gene and its medical references are also included in Table 5. In this section, we individually examine these 13 top ranked genes for relevance in the diagnosis of prostate cancer. All 13 genes have some relevance and deserve a more detailed analysis to understand their role in prostate cancer's development. The role of some of these biologically relevant genes can be easily explained because they code for proteins whose role in prostate cancer has long been identified and widely studied. Such is the case of the NELL2 gene. In situ hybridization analysis of hyperplastic prostate specimens demonstrated that 


\section{Prostate cancer}

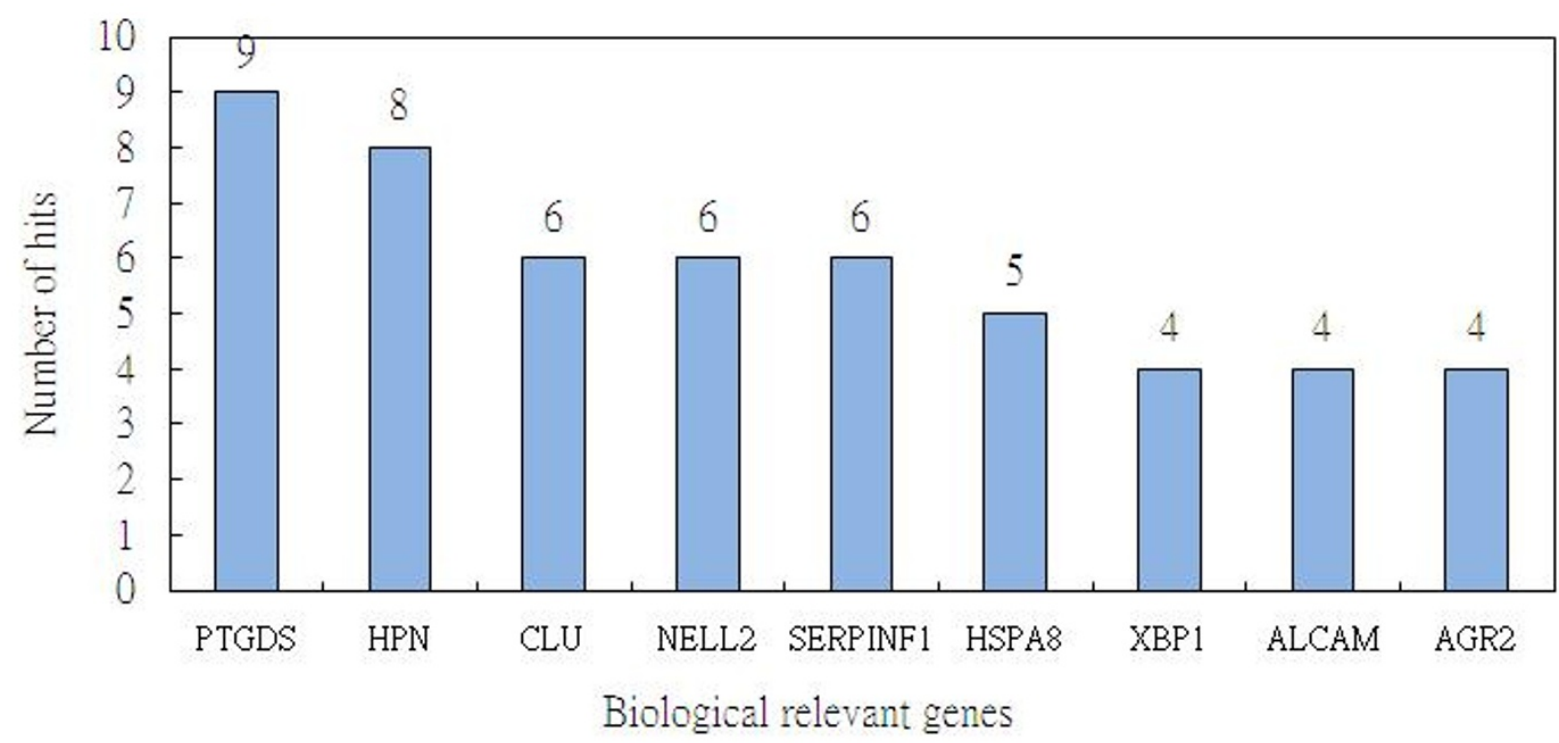

Figure 4 The average number of hits generated by the random forest method regarding biologically relevant genes in prostate cancer.

NELL2 mRNA expression is predominantly localized in basal cells of the epithelium. Disease-related changes in the levels of $N E \boldsymbol{L L} 2$ may contribute to alterations in epithelial-stromal homeostasis in $\mathrm{BPH}$ [48]. The presence of some other genes in our list can be explained by recently published studies. For example, the discovery that the GSTM1 gene, GSTM1, may be linked to prostate cancer risk was published only a year ago [49]. Another example is the ANGPT1 gene, published 2 years ago, where Ang-2 was expressed predominantly in prostate epithelial cells whereas Ang-1 (ANGPT1) was expressed in epithelium and smooth muscle [50].

We also list the roles of the rest of the biological genes shown in Table 5. The TNFSF10 gene: the FOXO family of forkhead transcription factors is implicated in TNFSF10 transcriptional activation in prostate carcinoma cells [51]. The S100A4 gene: $\mathbf{S 1 0 0 A 4}$ protein is expressed in neither benign nor malignant prostatic epithelium nor in LNCaP and Du145 cells. The mechanism underlying absent $\mathbf{S 1 0 0 A 4}$ expression in prostatic epithelium and cell lines may involve methylation [52]. The RBP1 gene: Altered $\boldsymbol{C R B P 1}$ expression and promoter hypermethylation occur in several tumours, these changes were investigated in prostate tumorigenesis [25]. The COL4A6 gene: COL4A6 expression is missing in nearly all cancerous tissues as evidenced by the Boolean function [53]. The PTGDS gene: Lipocalin-type prostaglandin D syntheses ( $L$-PGDS ) and prostaglandin D2
(PGD2) metabolites produced by normal prostate stromal cells inhibited tumor cell growth through a peroxisome proliferator-activated receptor gamma (PPARgamma)-dependent mechanism [54]. The SERBP1 gene: The expression of hepsin, uPA, PAI-RBP1 (SERBP1), PAI-1, and factor XIII may influence fibrinolysis and are regulated by the tumour microenvironment [55]. The LMO3 gene: The protein encoded in this gene is a LIMonly protein ( $\boldsymbol{L M O})$, which is involved in cell fate determination. This gene has been noted to up-regulate in the prostate cancer samples [56]. The DIO2 gene: Subtype II tumours represent the second clinically aggressive tumour subclass, and the gene expression feature that characterizes this subgroup includes several genes identified in supervised analysis to be associated with both high grade and advanced stage cancer, such as HDAC9 and DIO2 [57]. The TARP gene: TARP is exclusively expressed in the prostate in males and is up-regulated by androgen in LNCaP cells, an androgen-sensitive prostate cancer cell line [58]. The HPN gene: Xu L has identified a pair of robust marker genes (HPN and STAT6) by integrating microarray datasets from three different prostate cancer studies [59].

In Table 6, we summarize the results from related studies. Since few studies focus on identifying biologically relevant genes in cancers, we summarize their results based on the study's computing methods. We then compare all these 8 gene selection methods, including our two pro- 
Table 5: Functions of the biologically relevant genes found in prostate cancer.

\begin{tabular}{|c|c|c|}
\hline Gene Name & Gene Function & Evidence References \\
\hline HPN & $\begin{array}{l}\text { Plays an essential role in cell growth and } \\
\text { maintenance of cell morphology. }\end{array}$ & {$[59]$} \\
\hline S100A4 & S100 calcium binding protein A4. & {$[52]$} \\
\hline RBP1 & Intracellular transport of retinol. & {$[25]$} \\
\hline ANGPT1 & $\begin{array}{l}\text { Appears to play a crucial role in mediating } \\
\text { reciprocal interactions between the } \\
\text { endothelium and surrounding matrix and } \\
\text { mesenchyme. }\end{array}$ & {$[50]$} \\
\hline COL4A6 & $\begin{array}{l}\text { Type IV collagen is the major structural } \\
\text { component of glomerular basement } \\
\text { membranes (GBM), forming a 'chicken- } \\
\text { wire' meshwork together with laminins, } \\
\text { proteoglycans, and entactin/nidogen. }\end{array}$ & [53] \\
\hline NELL2 & $\begin{array}{l}\text { Chicken nel-like } 2 \text { homolog with a wide } \\
\text { and weak expression, expressed in adult } \\
\text { and fetal brain and hemopoietic cells } \\
\text { (nucleated peripheral blood cells) but not } \\
\text { in B cells. }\end{array}$ & [48] \\
\hline GSTM1 & $\begin{array}{l}\text { Conjugation of reduced glutathione to a } \\
\text { wide number of exogenous and } \\
\text { endogenous hydrophobic electrophiles. }\end{array}$ & [49] \\
\hline PTGDS & $\begin{array}{l}\text { It is likely to play important roles in both } \\
\text { maturation and maintenance of the } \\
\text { central nervous system and male } \\
\text { reproductive system. }\end{array}$ & {$[54]$} \\
\hline TARP & Transmembrane receptor activity. & {$[58]$} \\
\hline LMO3 & Lim domain only 3. & {$[56]$} \\
\hline $\mathrm{DIO} 2$ & $\begin{array}{l}\text { Essential for providing the brain with } \\
\text { appropriate levels of } \mathrm{T} 3(3,5,3 \text { '- } \\
\text { triiodothyronine) during the critical period } \\
\text { of development. }\end{array}$ & {$[57]$} \\
\hline SERBP1 & $\begin{array}{l}\text { May play a role in the regulation of mRNA } \\
\text { stability. }\end{array}$ & {$[55]$} \\
\hline TNFSF10 & $\begin{array}{l}\text { Induces apoptosis. Its activity may be } \\
\text { modulated by binding to the decoy } \\
\text { receptors TNFRSF10C/TRAILR3, } \\
\text { TNFRSF10D/TRAILR4 and TNFRSF11B/OPG } \\
\text { that cannot induce apoptosis. }\end{array}$ & {$[51]$} \\
\hline
\end{tabular}


Table 6: Comparison of related methods and results.

\begin{tabular}{|c|c|c|c|}
\hline Authors & Methods & Cancer Type & Results \\
\hline Ben-Tor et al. [27] & TNoM & Ovarian & $\begin{array}{l}\text { 4/137 (Among the top } 137 \\
\text { genes, } 8 \text { are cancer-related } \\
\text { genes. } 4 \text { genes (GAPDH, SLPI, } \\
\text { HE4 and keratin 18) are } \\
\text { ovarian genes.) }\end{array}$ \\
\hline \multirow[t]{13}{*}{ Covell et al. [60] } & SOM & Bladder & $\begin{array}{l}1 / 5 \text { ( } 1 \text { out of the top } 5 \text { genes is } \\
\text { a Bladder gene) }\end{array}$ \\
\hline & $\begin{array}{l}\text { Up-regulated in tumor cells } \\
\text { and down-regulated in } \\
\text { normal cells }\end{array}$ & Breast & $\begin{array}{l}1 / 3 \text { ( } 1 \text { out of the top } 3 \text { genes is } \\
\text { a Breast gene) }\end{array}$ \\
\hline & & CNS & $\begin{array}{l}5 / 62 \text { ( } 5 \text { out of the top } 62 \text { genes } \\
\text { are CNS genes) }\end{array}$ \\
\hline & & Colorectal & $\begin{array}{l}\text { 2/37 ( } 2 \text { out of the top } 37 \text { genes } \\
\text { are Colorectal genes) }\end{array}$ \\
\hline & & Leukemia & $\begin{array}{l}11 / 68 \text { ( } 11 \text { out of the top } 68 \\
\text { genes are Leukemia genes) }\end{array}$ \\
\hline & & Lung & $\begin{array}{l}1 / 4 \text { ( } 1 \text { out of the top } 4 \text { genes is } \\
\text { a Lung gene) }\end{array}$ \\
\hline & & Lymphoma & $\begin{array}{l}7 / 33 \text { ( } 7 \text { out of the top } 33 \text { genes } \\
\text { are Lymphoma genes) }\end{array}$ \\
\hline & & Melanoma & $\begin{array}{l}3 / 12 \text { ( } 3 \text { out of the top } 12 \text { genes } \\
\text { are melanoma genes) }\end{array}$ \\
\hline & & Mesothelioma & $\begin{array}{l}0 / 49 \text { ( } 0 \text { out of the top } 49 \text { genes } \\
\text { is a Mesothelioma gene) }\end{array}$ \\
\hline & & Pancreas & $\begin{array}{l}\text { 2/9 ( } 2 \text { out of the top } 9 \text { genes } \\
\text { are Pancreas genes) }\end{array}$ \\
\hline & & Prostate & $\begin{array}{l}6 / 36 \text { ( } 6 \text { out of the top } 36 \text { genes } \\
\text { are Prostate genes) }\end{array}$ \\
\hline & & Renal & $\begin{array}{l}4 / 26 \text { ( } 4 \text { out of the top } 26 \text { genes } \\
\text { are Renal genes) }\end{array}$ \\
\hline & & Uterine & $\begin{array}{l}1 / 42 \text { ( } 1 \text { out of the top } 42 \text { genes } \\
\text { is a Uterine gene) }\end{array}$ \\
\hline
\end{tabular}

posed novel methods, with the results in Table 6. In different cancer types and methods, very few biologically relevant genes are identified. Our methods, especially our proposed SVST method, are significantly superior to these. For example, in the leukemia dataset, the SVST method identifies 15 biologically relevant genes out of the top 25 while Covell et al. [60] identifies 11 biologically relevant genes out of the top 68 . In the prostate cancer dataset, the SVST method identifies 13 biologically relevant genes out of the top 25 while Covell et al. [60] identifies only 6 biologically relevant genes out of the top 36 .

\section{Statistically sound performance comparison among these 8} methods

As Ambroise and McLachlan [61] point out, the performance of a classification method may be overestimated when using the Leave-out-out method. In this study, therefore, we verified our experiment using a random average 3-fold method. This method randomly separates datasets into 3-folds and chooses one subset among the three as the validation set used to verify the model. The remaining two subsets are used as the model's training sets. The cross validation process is repeated 3 times with each of the three subsets used once for validation. This process is then repeated 100 times in order to gain a statistically impartial performance result for our model. In order to compare the classification performance of the 8 methods used in the paper, we used the SVM classifier with the linear kernel function and with default parameter settings.

The performance comparison of these 8 methods is summarized in Table 7. This table shows the average classification accuracy (with ranges in the parentheses) after running experiments for all 8 methods 100 times as discussed in this paper. For ease of visualization, we also 
Table 7: Statistically sound performance comparison for the leukemia dataset.

\begin{tabular}{ccccccc}
\hline Methods & $\mathbf{2 5}$ genes & $\mathbf{5 0}$ genes & $\mathbf{7 5}$ genes & $\mathbf{1 0 0}$ genes & $\mathbf{1 2 5}$ genes & $\mathbf{1 5 0}$ genes \\
\hline SNR & $.90(.87$ to 1$)$ & $.93(.87$ to .99$)$ & $.94(.89$ to .1$)$ & $.95(.87$ to .99$)$ & $.94(.88$ to 1$)$ \\
\hline t-Test & $.88(.67$ to 1$)$ & $.91(.66$ to .99$)$ & $.91(.69$ to .99$)$ & $.91(.65$ to 1$)$ & $.92(.69$ to .99$)$ & $.92(.64$ to 1$)$ \\
\hline LSD & $.85(.50$ to 1$)$ & $.88(.53$ to .95$)$ & $.89(.51$ to .94$)$ & $.89(.52$ to 1$)$ & $.87(.54$ to .97$)$ \\
\hline TNoM & $.73(.67$ to .91$)$ & $.73(.65$ to .90$)$ & $.73(.66$ to .91$)$ & $.73(.67$ to .90$)$ & $.76(.69$ to .92$)$ & $.75(.67$ to .92$)$ \\
\hline MDMR & $.91(.79$ to 1$)$ & $.93(.74$ to .98$)$ & $.93(.72$ to .96$)$ & $.94(.78$ to 98$)$ & $.94(.76$ to $) .1)$ & $.94(.79$ to .99$)$ \\
\hline WEPO & $.64(.46$ to .79$)$ & $.61(.51$ to .79$)$ & $.60(.50$ to 76$)$ & $.67(.52$ to 81$)$ & $.69(.50$ to .85$)$ & $.73(.53$ to .86$)$ \\
\hline RFGS & $.86(.75$ to .95$)$ & $.85(.76$ to .98$)$ & $.85(.75$ to .94$)$ & $.86(.75$ to .95$)$ & $.88(.78$ to .99$)$ \\
\hline SVST & $.95(.88$ to 1$)$ & $.98(.87$ to .99$)$ & $.97(.85$ to .1$)$ & $.98(.87$ to 1$)$ & $.98(.88$ to .99$)$ \\
\hline
\end{tabular}

drew a bar comparison as shown in Figure 5. The results clearly show the superior performance of our SVST method. Compared to the other 7 methods, SVST significantly improves upon the average classification accuracy rate from $5 \%$ to $30 \%$ for leukemia datasets.

The same approach is also applied to prostate cancer datasets. Table 8 summarizes the performance compari- son of 8 methods for analyzing prostate cancer datasets. A bar comparison is also shown in Figure 6. Once again, our SVST method demonstrates significant improvement in classification performance compared to 7 alternative methods. The average classification accuracy rate increased from $5 \%$ to $35 \%$ for prostate datasets. The results imply that the genes selected using the SVST not

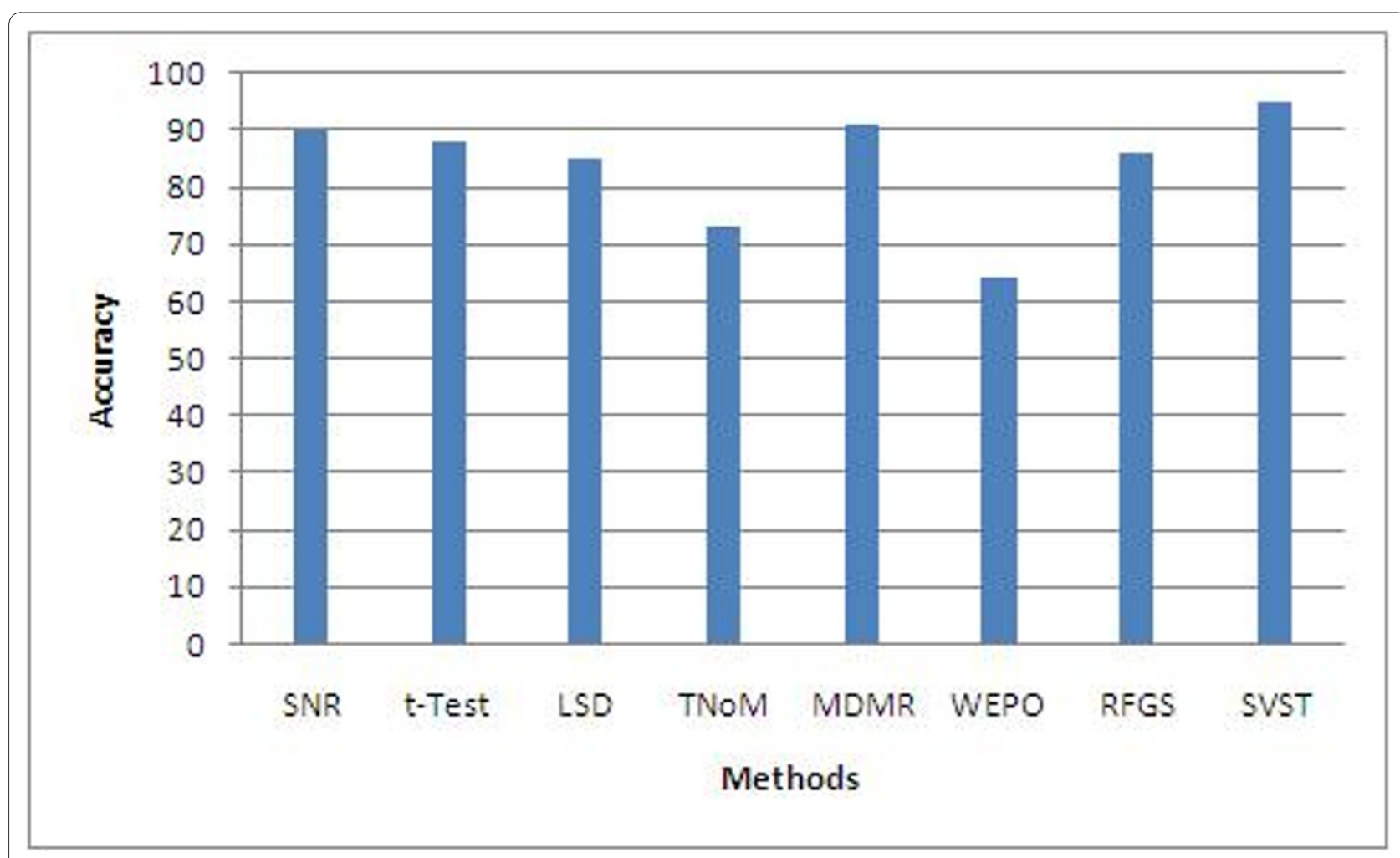

Figure 5 Statistically sound performance comparison among 8 methods for the leukemia dataset. 
Table 8: Statistically sound performance comparison for the prostate cancer dataset.

\begin{tabular}{ccccccc}
\hline Methods & $\mathbf{2 5}$ genes & $\mathbf{5 0}$ genes & $\mathbf{7 5}$ genes & $\mathbf{1 0 0}$ genes & $\mathbf{1 2 5}$ genes & $\mathbf{1 5 0}$ genes \\
\hline SNR & $.86(.82$ to .95$)$ & $.86(.82$ to .95$)$ & $.85(.80$ to .97$)$ & $.86(.83$ to .95$)$ & $.83(.80$ to .93$)$ & $.84(.82$ to .96$)$ \\
\hline t-Test & $.80(.67$ to .94$)$ & $.82(.66$ to .92$)$ & $.82(.67$ to .90$)$ & $.81(.67$ to .93$)$ & $.81(.68$ to .93$)$ & $.80(.69$ to .95$)$ \\
\hline LSD & $.79(.65$ to .94$)$ & $.81(.63$ to .93$)$ & $.81(.62$ to .95$)$ & $.81(.64$ to .95$)$ & $.81(.67$ to .94$)$ & $.82(.64$ to .93$)$ \\
\hline TNoM & $.65(.53$ to .80$)$ & $.65(.51$ to .78$)$ & $.63(.50$ to .79$)$ & $.65(.53$ to .80$)$ & $.65(.52$ to .78$)$ & $.63(.51$ to .81$)$ \\
\hline MDMR & $.87(.76$ to .95$)$ & $.84(.75$ to .97$)$ & $.86(.76$ to .98$)$ & $.86(.75$ to .97$)$ & $.87(.78$ to .95$)$ & $.87(.74$ to .98$)$ \\
\hline WEPO & $.56(.43$ to .70$)$ & $.57(.44$ to .69$)$ & $.67(.53$ to .74$)$ & $.70(.55$ to .79$)$ & $.68(.52$ to .75$)$ & $.73(.64$ to .86$)$ \\
\hline RFGS & $.80(.65$ to .91$)$ & $.81(.68$ to .92$)$ & $.78(.63$ to .91$)$ & $.82(.68$ to .92$)$ & $.79(.65$ to .90$)$ & $.81(.67$ to .92$)$ \\
\hline SVST & $.92(.85$ to .95$)$ & $.90(.83$ to .96$)$ & $.91(.84$ to .95$)$ & $.92(.87$ to .94$)$ & $.92(.82$ to .95$)$ \\
\hline
\end{tabular}

only are more biologically relevant but are also more informative with regards to the diagnosis and treatment of both leukemia and prostate cancers.

Preliminary study of gene-gene interaction of biologically relevant leukemia genes identified by the SVST method

Due to the superior characteristics of our SVST method (i.e. identifying a greater number of biologically relevant genes and yielding better classification accuracy rates), we would like to further investigate the possible genegene interactions among these biologically relevant genes. Our hypothesis is that the gene-gene interactions among these biologically relevant genes, if present, may provide additional benefits with regards to the diagnosis of cancers. As a preliminary study, we ran the experiment

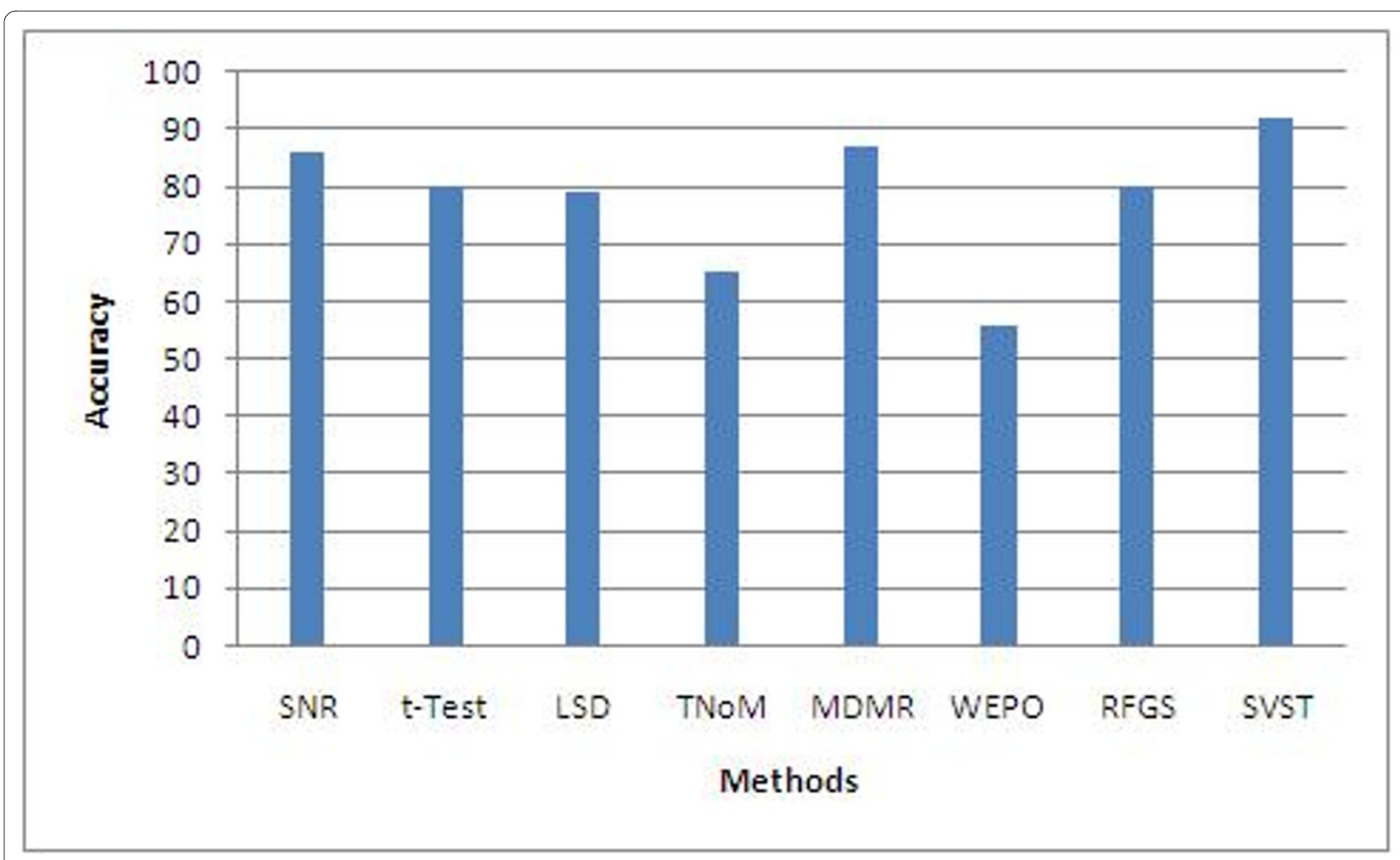


Table 9: The gene-gene interaction among identified leukemia genes.

\begin{tabular}{|c|c|c|c|}
\hline $\begin{array}{c}\text { Biologically relevant } \\
\text { gene1 }\end{array}$ & $\begin{array}{c}\text { Number of interacted } \\
\text { gene }\end{array}$ & $\begin{array}{l}\text { Bridge gene between } \\
\text { gene } 1 \text { and gene } 2\end{array}$ & $\begin{array}{c}\text { Biologically relevant } \\
\text { gene2 }\end{array}$ \\
\hline \multirow[t]{3}{*}{$Z Y X$} & 15 & NEDD9 & TCF3 \\
\hline & & ATXN1 & CST3 \\
\hline & & TES & SPTAN1 \\
\hline \multirow[t]{2}{*}{ TCF3 } & 47 & NEDD9 & ZYX \\
\hline & & CREBBP & HOXA9 \\
\hline \multirow[t]{2}{*}{ CD33 } & 3 & PTPN6 & CD79A \\
\hline & & SRC & SPTAN1 \\
\hline CD63 & 13 & HLADRA & TCRA \\
\hline \multirow[t]{2}{*}{ TCRA } & 15 & HLADRA & CD63 \\
\hline & & HSPA5 & MPO \\
\hline \multirow[t]{4}{*}{ SPTAN1 } & 46 & ACTB & MPO \\
\hline & & CASP3 & IL18 \\
\hline & & TES & ZYX \\
\hline & & SRC & $\mathrm{CD} 33$ \\
\hline \multirow[t]{2}{*}{ MPO } & 35 & ACTB & SPTAN1 \\
\hline & & HSPA5 & TCRA \\
\hline CST3 & 9 & ATXN1 & $Z Y X$ \\
\hline HOXA9 & 13 & CREBBP & TCF3 \\
\hline CD79A & 16 & PTPN6 & CD33 \\
\hline MACMARCKS & 1 & & - \\
\hline CCND3 & 26 & & - \\
\hline PSMB9 & 13 & & - \\
\hline IL18 & 8 & CASP3 & SPTAN1 \\
\hline STOM & 8 & - & \\
\hline
\end{tabular}




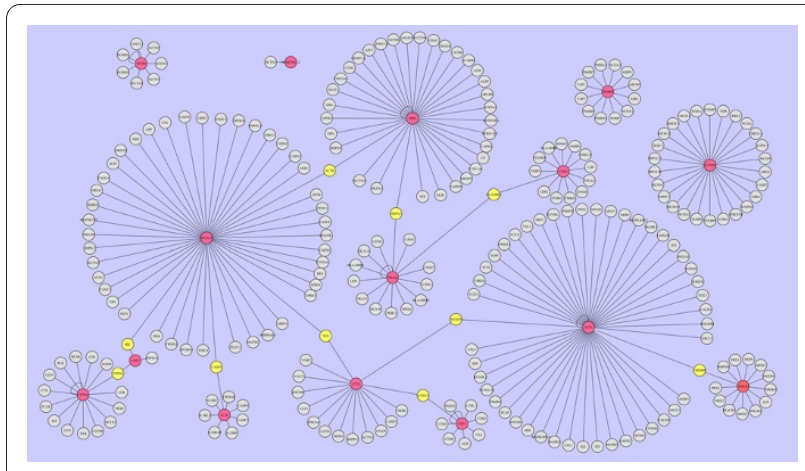

Figure 7 The gene-gene interaction graph of biologically relevant leukemia genes identified by the SVST method.

using 15 biologically relevant genes selected from a leukemia dataset. At first, we screened several protein-protein interaction (PPI) websites, and we found the IPIR (integrated protein interaction resource, http:// ymbc.ym.edu.tw/ipir/) to be an excellent tool for building PPI graphs of leukemia gene products. The IPIR is a powerful web tool which retrieves protein-protein interaction information from BIND, DIP, HPRD, MINT, MIPS, and IntAct databases.

The protein-protein interaction graph based on the 15 biologically relevant leukemia genes selected using the SVST method is displayed in Figure 7. The name of each gene is viewable by expanding the scale of graph. In Figure 7, we find that 11 biologically relevant genes (marked in red) out of 15 genes form a PPI graph. To further understand the relationships among these genes, we summarize the neighbourhood genes and bridge genes in Table 9. The 11 biologically relevant genes we found which have interactions are ZYX, TCF3, CD33, CD63, TCRA, SPTAN1, MPO, CST3, HOXA9, CD79A, and IL18. Among these 11 genes, TCF3 has the largest number of interacting genes (47). SPTAN1 has the second largest number of interacted genes (46), and the remaining 9 genes (with the number of interacting genes shown in the subsequent parentheses) are: MPO (35), CD79A (16), ZYX (15), TCRA (15), CD63 (13), HOXA9 (13), CST3 (9), IL18 (8), and CD33 (3).

There are several sub-networks among these genes. For instance, the sun-network links ZYX with TCF3, CST3, and SPTAN1via NEDD9, ATXN1, and TES, respectively (marked in yellow). The sun-network links TCF3 with ZYX and HOXA9 via NEDD9 and CREBBP, respectively. The sun-network links CD33 with CD79A and APTAN1 via PTPN6 and SRC, respectively. The sun-network links CD63 with TCRA via HLADRA. The sun-network links TCRA with CD63 and MPO via HLADRA and HSPA5, respectively. The sun-network links SPTAN1 with MPO, IL18, ZYX, and CD33 via ACTB, CASP3, TES, and SRC, respectively. The sun-network links MPO with SPTAN1 and TCRA via ACTB and HSPA5, respectively. The sunnetwork links CST3 with ZYX via ATXN1. The sun-network links HOXA9 with TCF3 via CREBBP. The sun-network links CD79A with CD33 via PTPN6. The sunnetwork links IL18 with SPTAN1 via CASP3.

Whether the identified PPI graph is the key mechanism to better classification performance currently remains unproven and is beyond the scope of this particular paper. However, our SVST method has the capability to identify a group of biologically relevant leukemia genes with a significant gene-gene interaction relationship. We believe this finding merits further study.

\section{Conclusions}

It is difficult in cancer research to identify sensitive and specific gene markers. In order to overcome problems caused by high dimensional input spaces, accurate and efficient gene selection methods are critical. Traditional selection approaches, however, do not consider the quality of the samples they analyze, the result of which affects the selection of biologically relevant genes.

In this paper, we have proposed two novel gene selection algorithms, the SVST and the RFGS methods. Both identify more biologically relevant genes concerning leukemia and prostate cancer. The proposed RFGS method is capable of searching for a global optimal or near optimal subset of genes due to their randomized characteristics. The proposed SVST method first extracts quality samples (i.e. support vector samples located only on support vectors) and avoids selecting incorrect genes. These quality samples are then used to form an optimal subset of genes that have a better chance to be biologically relevant.

We demonstrate experimentally that our proposed RFGS and SVST methods identify more genes relevant to cancers. Our proposed RFGS method has the ability to identify an average of 9 biologically relevant genes out of the top 25 genes in both leukemia and prostate cancers. Our proposed SVST method produces the best results among all 8 methods. From the top 25 genes selected using SVST method, we find that 15 are biologically relevant in patients with leukemia and 13 genes are biologically relevant in patients with prostate cancers. In contrast to traditional statistical methods, which only identify 8 or less genes in patients with leukemia and 8 or less genes in patients with prostate cancer, our methods yield significantly better results. The significance of identifying biologically relevant genes cannot be understated; research in the fields of biology and medicine can benefit substantially from the identification of biologically relevant genes to confirm recent discoveries in cancer research or suggest new avenues for exploration. 


\section{Authors' contributions}

AHC initialed the study, designed the computational experiments, validated the results, drafted the manuscript, and obtained funding. YWT and CHL were involved in data acquisition, codes writing and testing. All authors were involved in data analysis and critical revision of the manuscript. All authors read and approved the final manuscript.

\section{Acknowledgements}

The authors thank the National Science Council for their financial support regarding project NSC 98-2221-E-320-005

\section{Author Details}

1'Department of Medical Informatics, Tzu Chi University, No.701, Sec. 3, Jhongyang Rd. Hualien City, Hualien County 97004, Taiwan and 2Graduate Institute of Medical Informatics, Tzu Chi University, No.701, Sec. 3, Jhongyang Rd. Hualien City, Hualien County 97004, Taiwan

Received: 26 November 2009 Accepted: 30 April 2010 Published: 30 April 2010

\section{References}

1. Cho R, Campbell J, Winzeler E, Steinmetz L, Conway A, Wodicka L, Wolfsberg T, Gabrielian A, Landsman D, Lockart D: A genome-wide transcriptional analysis of the mitotic cell cycle. Mol Cell 1998, 2:65-73.

2. De Risi J, lyer V, Brown P: Exploring the metabolic and genetic control of gene expression on a genomic scale. Science 1997, 278:680-686

3. Friedman N, et al:: Using Bayesian networks to analyze expression data. Journal of Computational Biology 2000, 7(3-4):601-620.

4. Chen JJ, et al:: Global analysis of gene expression in invasion by a lung cancer model. Cancer Research 2001, 61:5223-5230.

5. Morley M, et al:: Genetic analysis of genome-wide variation in human gene expression. Nature 2004, 430:743-747.

6. Statnikov A, Aliferis CF, Tsamardinos I, Hardin D, Levy S: A comprehensive evaluation of multicategory classification methods for microarray gene expression cancer diagnosis. Bioinformatics 2005, 21:631-643.

7. Ramaswamy S, et al: Multiclass cancer diagnosis using tumour gene expression signatures. Proc Natl Acad Sci USA 2001, 98:15149-15154.

8. Hastie T, Tibshirani R, Eisen M, Brown P, Ross D, Scherf U, Weinstein J, Alizadeh A, Staudt L, Botstein D: Gene Shaving: a new class of clustering methods for expression arrays. Stanford University Technical report 2000.

9. Tamayo P, Slonim D, Mesirov J, Zhu Q, Kitareewan S, Dmitrovsky E, Lander E, Golub T: Interpreting patterns of gene expression with selforganizing maps. Proc Natl Acad Sci USA 2000, 96:2907-2912.

10. Goldberg DE: Genetic Algorithms in Search, Optimization, and Machine Learning. Addison-Wesley Reading, MA; 1989.

11. Greer BT, Khan J: Diagnostic classification of cancer using DNA microarrays and artificial intelligence. Ann N Y Acad Sci 2004, 1020:49-66.

12. Li L, Weinberg RC, Darden TA, Pedersen LG: Gene selection for sample classification based on gene expression data: study of sensitivity to choice of parameters of the GA-KNN method. Bioinformatics 2001, 17:1131-1142.

13. Berthold F, Schwab M, Antonescu CR, Peterson C, Meltzer PS: Classification and diagnostic prediction of cancers using gene expression profiling and artificial neural networks. Nature Medicine 2001, 7:673-679.

14. Tan AC, Gilbert D: Ensemble machine learning on gene expression data for cancer classification. Applied Bioinformatics 2003, 2:75-S83.

15. Prinzie A, Poel D Van den: Random forests for multiclass classification: Random multinomial logit. Expert Systems with Applications 2008, 34:1721-1732

16. Chang C, Lin CJ: LIBSVM: a library for support vector machines. 2003 [http://www.csie.ntu.edu.tw/ cjlin/libsvm/].

17. Cortes, Vapnik : Support vector networks, Mach. Learning 1995, 20:273-297.

18. Holland JH: Adaptation in Natural and Artificial Systems. Prostate 1999, 40:14.

19. Jemal A, Siegel R, Ward E, Murray T, Xu J, Thun MJ: Cancer statistics 2007 CA Cancer J Clin 2007, 57:43-66

20. Ewens WJ, Grant GR: Statistical Methods in Bioinformatics: An Introduction (Statistics for Biology and Health). Springer-Verlag press; 2005.
21. Munro BH: Statistical Methods for Health Care Research. Lippincott Williams \& Wilkins; 2004

22. Dudoit S, Laan M, Keles S, Cornec M: Unified crossvalidationmethodology for estimator selection and application to genomic. Bulletin of the International Statistical Institute, 54th Session Proceedings 2003, LX(Book 2):412-415.

23. Golub TR, Slonim DK, Tamayo P, Huard C, Gaasenbeek M, Mesirov JP, Coller H, Loh ML, Downing JR, Caligiuri MA, Bloomfield CD, Lander ES: Molecular classification of cancer: class discovery and class prediction by gene expression monitoring. Science 1999, 286:531-537.

24. Slonim D, Tamayo P, Mesirov J, Golub T, Lander E: Class prediction and discovery using gene expression data. In Proceedings of the 4th Annual International Conference on Computational Molecular Biology (RECOMB) Universal Academy Press, Tokyo, Japan; 2000:263-272.

25. Jeronimo C, Henrique R, Oliveira J, Lobo F, Pais I, Teixeira MR, Lopes C: Aberrant cellular retinol binding protein 1 (CRBP1) gene expression and promoter methylation in prostate cancer. Journal of Clinical Pathology 2004, 57:872-876.

26. Longnecker R: Epstein-Barr virus latency: LMP2, a regulator or means for Epstein-Barr virus persistence? Adv Cancer Res 2000, 79:175-200.

27. Ben-Dor A, et al:: Tissue Classification with Gene Expression Profiles. Journal of Computational Biology 2000, 7:559-583.

28. Park PJ, Pagano M, Bonetti M: A Nonparametric Scoring Algorithm for Identifying Informative Genes from Microarray Data. Pacific Symposium on Biocomputing 2001, 6:52-63.

29. Chen T, He HL, Church GM: Modeling Gene Expression with Differential Equations. Proc. of Pacific Symposium on Biocomputing 1999:29-40.

30. Chuang HY, Tsai HK, Tsai YF, Kao CY: Ranking genes for discriminability on microarray data. Journal of Information Science and Engineering 2003, 19:953-966.

31. Breiman L: Random forests. Machine Learning 2001, 45:5-32.

32. Liu Z, Meng X: Integration of Improved BPNN Algorithm and Multistage Dynamic Fuzzy Judgement and Its Application on ESMP Evaluation. Journal of computers 2009, 4(1):

33. Thorsteinsdottir U, Krosl J, Kroon E, Haman A, Hoang T, Sauvageau G: The oncoprotein E2APbx1a collaborates with Hoxa9 to acutely transform primary bone marrow cells. Molecular Cell Biology 1999, 19(9):6355-6366.

34. Harlan DM, Graff JM, Stumpo DJ, Eddy RL Jr, Shows TB, Boyle JM, Blackshear PJ: The human myristoylated alanine-rich $\mathrm{C}$ kinase substrate (MARCKS) gene (MACS). Analysis of its gene product, promoter, and chromosomal localization. Journal of Biological Chemistry 1991, 266(22):14399-14405.

35. Sperr WR, Florian S, Hauswirth AW: Valent, CD33 as a target of therapy in acute myeloid leukemia: current status and future perspectives. Leuk Lymphoma 2005, 46:115-1120.

36. Macalma T, Otte J, Hensler ME, Bockholt SM, Louis HA, Kalff-Suske M, Grzeschik KH, Ahe D von der, Beckerle MC: Molecular haracterization of human zyxin. Journal of Biological Chemistry 1996, 271(49):31470-31478.

37. Barber KE, Harrison CJ, Broadfield ZJ, Stewart AR, Wright SL, Martineau M: Molecular cytogenetic characterization of TCF3 (E2A)/19p13.3 rearrangements in B-cell precursor acute lymphoblastic leukemia. Genes Chromosomes Cancer 2007, 46:478-486.

38. Leinoe EB, Hoffmann MH, Kjaersgaard E, Johnsen HE: Multiple platelet defects identified by flow cytometry at diagnosis in acute myeloid leukemia. Br J Haematol 2004, 127(1):76-84.

39. De Schouwer PJ, Dyer MJ, Brito-Babapulle VB, Matutes E, Catovsky D, Yuille MR: T-cell prolymphocytic leukemia: antigen receptor gene rearrangement and a novel mode of MTCP1 B1 activation. $\mathrm{Br} J$ Haematol 2000, 110:831-838.

40. Upender M, Gallagher PG, Moon RT: Localization of human alpha-fodrin gene (SPTAN1) to 9q33-q34 by fluorescence in situ hybridization. Cytogenet Cell Genet 1994, 66:39-41.

41. Zuo Z, Lu WP, Yu JB, Li JM, Liao DY: Extramedullary infiltration of acute monocytic leukemia/monoblastic sarcoma: a clinicopathologic and immunophenotype analysis of 5 cases. Zhonghua bing lixue za zhi Chinese journal of pathology 2008, 37(1):27-30.

42. Sun Y, Dong LJ, Tian F, Wang SQ, Jia ZL, Huang J: Identification of acute leukemia-specific genes from leukemia recipient/sibling donor pairs by distinguishing study with oligonucleotide microarrays. Zhongguo Shi Yan Xue Ye Xue Za Zhi (article in Chinese) 2004, 4(12):450-454. 
43. Astsaturov IA, Matutes E, Morilla R, Seon BK, Mason DY, Farahat N, Catovsky D: Differential expression of B29 (CD79b) and mb-1 (CD79a) proteins in acute lymphoblastic leukemia. Leukemia 1996, 10:769-773.

44. Smith ML, Arch R, Smith LL: Development of a human acute myeloid leukemia screening panel and consequent identification of novel gene mutation in FLT3 and CCND3. Br J Haematol 2005, 128:318-23.

45. Taniguchi M, Nagaoka K, Kunikata T, Kayano T, Yamauchi H, Nakamura S, Ikeda M, Orita K, Kurimoto M: Characterization of anti-human interleukin-18 (IL-18)/IFN- $\gamma$-inducing factor (IGIF) monoclonal antibodies and their application in the measurement of human IL-18 by ELISA. J Immunol Methods 1997, 206:107.

46. Gilles F, Glenn M, Goy A, Remache Y, Zeelentz A: A novel gene STORP (stomatin related protein) is localized $2 \mathrm{~kb}$ upstream of the promyelocytic gene on chromosome 15q22. Eur J Haematol 2000, 64:104-113.

47. Singh D, et al:: Gene expression correlates of clinical prostate cancer behavior. Cancer Cell 2002, 1:203-209.

48. DiLella AG, Toner TJ, Austin CP, Connolly BM: Identification of genes differentially expressed in benign prostatic hyperplasia. $J$ Histochem Cytochem 2001, 49(5):669-670.

49. Li M, Guan TY, Li Y, Na YQ: Polymorphisms of GSTM1 and CYP1A1 genes and their genetic susceptibility to prostate cancer in Chinese. Chin Med J 2008, 121:305-308.

50. Wang GM, Kovalenko B, Huang Y, Moscatelli D: Vascular endothelial growth factor and angiopoietin are required for prostate regeneration. Prostate 2007, 67:485-99.

51. Modur V, Nagarajan R, Evers BM, Milbrandt J: FOXO proteins regulate tumor necrosis factor-related apoptosis inducing ligand expression. Implications for PTEN mutation in prostate cancer. J Biol Chem 2002 277:47928-47937.

52. Rehman I, Goodarzi A, Cross SS, Leiblich A, Catto AW, Phillips JT, Hamdy FC: DNA methylation and immunohistochemical analysis of the S100A4 calcium binding protein in human prostate cancer. The Prostate 2007, 67(4):341-347.

53. Dehan P, Waltregny D, Beschin A, Noel A, Castronovo V: Loss of type IV collagen alpha 5 and alpha 6 chains in human invasive prostate carcinomas. Am J Pathol 1997, 151:1097-1104.

54. Kim J, Yang P, Suraokar M, Sabichi AL, Llansa ND, Mendoza G, Subbarayan V, Logothetis CJ, Newman RA, Lippman SM: Suppression of prostate tumor cell growth by stromal cell prostaglandin D syntheses-derived products. Cancer Res 2005, 65:6189-6198.

55. Morrissey C, True LD, Roudier MP: Differential expression of angiogenesis associated genes in prostate cancer bone, liver and lymph node metastases. Clin Exp Metastasis 2008, 25:377-388.

56. Uzma SS, Robert HG: BFingerprinting the Diseased Prostate: Associations between BPH and Prostate Cancer. J Cell Biochem 2004, 91:161-169.

57. Lapointe J, et al:: Gene expression profiling identifies clinically relevant subtypes of prostate cancer. Proc Nat/ Acad Sci USA 2004, 101:811-816.

58. Maeda H, Nagata S, Wolfgang CD, Bratthauer GL, Bera TK, Pastan I: The T cell receptor gamma chain alternate reading frame protein (TARP), a prostate-specific protein localized in mitochondria. J Biol Chem 2004, 279:24561-24568

59. Xu L, Tan AC, Naiman DQ, Geman D, Winslow RL: Robust prostate cancer marker genes emerge from direct integration of inter-study microarray data. Bioinformatics 2005, 21:3905-3911.

60. Covell DG, Wallqvist A, Rabow AA, Thanki N: Molecular Classification of Cancer: Unsupervised Self-Organizing Map Analysis of Gene Expression Microarray Data. Molecular Cancer Therapeutics 2003, 2:317-332.

61. Ambroise C, McLachlan GJ: Selection bias in gene extraction on the basis of microarray gene-expression data. PNAS 2002, 99(10):6562-6566

\section{Submit your next manuscript to BioMed Central} and take full advantage of:

- Convenient online submission

- Thorough peer review

- No space constraints or color figure charges

- Immediate publication on acceptance

- Inclusion in PubMed, CAS, Scopus and Google Scholar

- Research which is freely available for redistribution 